\title{
La narrativa (1975-1997)
}

\author{
Silvia GaSPAR
}

Desde los albores del siglo XX las letras gallegas han tenido una preocupación prioritaria: el desarrollo del género narrativo. De hecho, venciendo el enorme peso de la tradición poética, la consolidación de una prosa narrativa concitó durante el primer cuarto de siglo el interés y el esfuerzo de los autores en general, pero en especial de aquéllos que percibían de un modo más intenso el sentimiento de pertenecer a una comunidad nacional. Así, desde las colecciones de novela breve en tiempos de las Irmandades da Fala hasta las producciones novelescas de la época Nós se asienta en la sociedad literaria la idea (después sobradamente teorizada) de la narración como género de las comunidades estables. Ni que decir tiene que el fracaso de la construcción nacional que sobrevino con la guerra civil de 1936 imprimió un sentimiento de frustración común a toda la posguerra, a pesar de los aparentes repuntes desde los años 50. En estas condiciones, el despegue de la narrativa seguiría siendo una asignatura pendiente.

Pero las expectativas sociales que se abrían a partir de 1975 reactivan la vieja cuestión: ya no se trata sólo de la narrativa (floreciente desde la década anterior), sino de un proyecto más definitivo. De este modo, en los años del postfranquismo se vuelve a evidenciar la cada vez mayor necesidad de consolidar las letras gallegas, pero usando para ello la herramienta novelesca. Arraiga así el mito de la gran novela, ente vertebrador de deseos y realizaciones de una comunidad en activo. A este propósito se van disponiendo diversos instrumentos (en la mayor parte de los casos, de forma no deliberada) que poco a poco se articulan, reunidos por una fuerza tácita pero inmanente que los conduce: el deseo de construir una comunidad nacional de sueños, de palabras y de hechos. En este confuso momento de crisis se inicia un primer impulso que se apresta a regenerar desde todos los frentes la aún nonnata autonomía (cultural, al tiempo que política) de Galicia. De este modo, de forma casi imperceptible pero ya imparable, se pone en marcha un proceso de regeneración literaria que llega hasta nuestros días, y que afecta de forma sustancial al panorama 
narrativo. Este cambio, en cualquier caso, se realiza en dos movimientos consecutivos, debido cada uno a las variables cronológicas y sociales que se iban conjugando. Dos movimientos que podemos definir como de creación de un nuevo centro el uno, y de expansión, el otro.

\section{LA CREACIÓN DE UN NUEVO CENTRO}

El período literario que aquí observamos (1975-1997) se halla, pues, regido por fuerzas de signo social que parten del fin de la dictadura franquista y se revigorizan con la puesta en marcha de la nueva comunidad autonómica; esto es, desde 1981. En el tiempo difuso que media entre ambos acontecimientos se abre un paréntesis de ajuste en el que se impone la sustitución de todos los referentes. De este modo, a la pérdida evidente de los valores políticos y sociales vigentes hasta ese momento, la década de los 70 añade la desaparición de los pilares culturales más prestigiosos: entre 1976 y 1981 mueren Ramón Otero Pedrayo, Eduardo Blanco-Amor y Álvaro Cunqueiro, máximos representantes de la tradición literaria que aún vinculaba a Galicia con la dorada época de Nós y con la renovación de la postguerra.

\section{A) LA NUEVA CÚPUla LITERARIA}

En ese momento toman el relevo autores que, tras su brillante aparición en el decenio anterior, se hallan ahora en fase de consolidación. Son los nombres más activos y destacados de la Nova Narrativa Galega (NNG) quienes entonces acceden a esa posición patriarcal que en todo momento parece dominar las letras gallegas: Xosé Luís Méndez Ferrín y Carlos Casares encabezan, casi en solitario, un elenco que el paso del tiempo acaba por diversificar y aun diluir. Efectivamente, mientras la producción de María Xosé Queizán ou Xohana Torres se espacia respecto de aquellas primeras y prometedoras creaciones $(A$ orella no buraco y Adiós María, respectivamente), otros nuevos narradores que ya gozaban de buen nombre desaparecen de la escena literaria - eso sucede con Rodríguez Mourullo y Suárez Llanos-, al tiempo que se integran en la prosa otras voces procedentes de la parcela poética - como Fernández Ferreiro-. En cualquier caso, de ese reajuste que augura el fin de la dictadura surgen las coordenadas que regirán el mundo narrativo en los años siguientes. De hecho, podemos decir que el postfranquismo en Galicia se abre en 1975 con Xoguetes pra un tempo prohibido, de Carlos Casares; desde este momento, el nombre del autor ourensano se reafirma como uno de los puntales de las letras del país, sobre todo con la publicación de Os escuros soños de Clío (1979) e Ilustrísima (1980). Fiel analista del momento en que vive, Casares acostumbra 
a utilizar el pasado -infancia y juventud en Xoguetes; el inicio de nuestro siglo en Ilustrísima - como rol de disfraces para proponer una reflexión sobre el presente. Esa visión a la vez crítica y constructiva, humorística y poco esperanzada, se ha ido manteniendo en sus últimas creaciones (Os mortos daquel verán, en 1987, y Deus sentado nun sillón azul, en 1996), tan espaciadas como fructíferas, pues cada una de ellas supone un nuevo giro de tuerca en la depuración del estilo, ya definitivamente orientado a la máxima concisión, pero siempre potenciando la agilidad expositiva y los mayores registros de significación. Así su última novela, Deus sentado..., que, a través de una estructura sometida a un tratamiento temporal extremo, nos muestra una historia de crueldad y raciocinio que cuestiona tanto el rol social del intelectual como el propio concepto de creación literaria.

La figura de Casares resulta, vista a una cierta distancia, muy reveladora del pulso literario de este pequeño país. En efecto, los asuntos y los enfoques a los que se aplica podrían hacer de sus obras auténticas marcas cronológicas ${ }^{1}$ para nuestro sistema literario: de este modo, así como Xoguetes... representa el inicio de la novela postfranquista, Os mortos... marca la definitiva ruptura con la época anterior, al tiempo que Deus sentado... nos devuelve a una narrativa comprometida pero básicamente preocupada por la funcionalidad artística.

En el otro platillo de la balanza, Xosé Luís Méndez Ferrín acrisola su maestría con periódicas entregas entre las que brillan Crónica de nós (1980) y Amor de Artur (1982). Son estos años en los que Médez Ferrín aún cultiva una narración ecléctica, en ocasiones todavía cercana a la producción de la NNG (así en Antón e os inocentes, de 1976). Presenciamos, en definitiva, un momento en el que las situaciones del absurdo —existencial, nacional — dan paso a la creación de un mundo que transita por un lugar próximo al realismo mágico - siempre de carácter simbólico, con evocación de las sagas míticas celtas- . Pero - también en su caso- el prolongado silencio durante los años que siguieron no será más que un repliegue de medios que se encaminan definitivamente hacia el cuento de tema fantástico, entre cuya brillantez técnica siempre es posible la lectura del mito nacional. El relato casi de iniciación Arnoia, Arnoia (1985) y Bretaña, esmeraldina (1988) —que no satisfizo las expectativas de crítica y público- constituyeron dos discretas avanzadillas de lo que en 1991 justificó, por deslumbrante, el silencio anterior: el libro de cuentos Arraianos: aquí, el leitmotiv de los orígenes (de enorme intensidad emocional) se aúna con la maestría formal y, sobre todo, léxica (se da un admirable aprovechamiento de las variantes dialectales).

Pero también el caso de Méndez Ferrín escapa a la simple individualidad, pues ostenta, junto con Casares, una posición sólidamente referencial para

\footnotetext{
' En la misma tesitura se sitúan algunos otros autores, al parecer particularmente sensibles a los movimientos sociales. En este grupo - al que tampoco es ajeno Ferrín- llama poderosamente la atención Anxo Rey Ballesteros, cuyas dos únicas novelas (Dos anxos e dos mortos y Loaira) han sido repetidamente consideradas como índice de un pensamiento grupal (reflexión desencantada de un tiempo).
} 
otros autores y aun para sectores del panorama cultural más vasto. De hecho, se puede hablar de una escuela de narración ferriniana, a la que se adscriben nombres como Darío Xohán Cabana, entre otros.

B) Fortalecimiento de la NARRATiva

La república de letras siempre ha sido consciente de la función social de la novela como vertebradora de los deseos y realizaciones de una comunidad en activo. La novela, como representación de la potencialidad de una comunidad, de un país, de un pasado y de un presente será el objetivo primordial de aquel momento. De ahí que la década de los 80 se abra a factores instrumentales que potencien el desarrollo de la narrativa y, en especial, de la novela. Al premio de narraciones Modesto R. Figueiredo, instituido en 1976, seguirán el Chitón y Blanco-Amor, ambos de novela y en 1981, el de la Universidad de Santiago (1983) y el Xerais (1984; cuatro años más tarde haría suyo el lema "A forza dos lectores"). La puerta de los 90 diversifica esta oferta de galardones con los premios García Barros, Torrente Ballester, Semana Negra, Cidade de Lugo y Álvaro Cunqueiro, que asumían un cariz más circunstancial y aun político, y menos militante que los anteriores. Ni que decir tiene que esta mayor oferta (sobre todo de cara al público curioso) se materializó en una mayor actividad editorial (que a los nombres clásicos de Galaxia y $O$ Castro sumaba los de Xerais, Sotelo Blanco, Ir Indo y Do Cumio antes de 1990).

\section{C) LA PROMOCIÓN DE LOS PREMIOS}

Como consecuencia de ese despliegue de medios que facilitan el desarrollo de la prosa surge una variada nómina de autores que cultivan primero el relato, pero que inmediatamente se entregan a la construcción del género novela. Son lo que se conoció —en la célebre etiqueta acuñada por Basilio Losada- como "Promoción do Pedrón de Ouro" y también "Promoción do Chitón". Así se dan a conocer autores como Xavier Alcalá, Alfredo Conde, Úrsula Heinze y Xosé Manuel Martínez Oca, entre otros. Con no tener en común ni unas marcas generacionales ni una intencionalidad específica, sí mantienen, en cambio, una trayectoria similar hasta 1984 , año que tomaremos como barrera cronológica para este primer período de habilitación de un espacio social y literario posible. De este modo, es en los llamados "años de la preautonomía" (1980-82) cuando surgen estos narradores con la indudable fuerza que aportaban sus obras. Así, Xavier Alcalá será para siempre el creador de Fábula y $A$ nosa cinza (en 1980 ambas), novelas que eclipsaron a la también notable Nos pagos de Huinca Loo (1982), a la malograda Tertulia (1985) y aun a los años 
de silencio que le siguieron; y aún hoy, cuando Alcalá se ha mostrado como autor de relatos (Contos do Impaís, Contos das Américas), de crónicas (Viaxes no país de Elal, 1992) y ha demostrado su magnífico potencial fabulador (Código Morse, 1996), no se puede aludir a su figura sin recordar aquellas dos memorables aportaciones.

También arropados por sendos premios se daban a conocer a principios de los 80 dos figuras que, con poca producción, pronto se abrieron paso hacia los primeros puestos: Víctor Fernández Freixanes, con $O$ Triángulo inscrito na circunferencia (1982), iniciaba una brillante carrera como escritor de titánicas novelas que ahondan en la construcción de la memoria nacional, y en las que las fantasmagorías dan la mano al más despiadado realismo para hacerse con el control de la propia palabra y de la propia Historia. En efecto, en la misma línea estan $O$ enxoval da noiva (1988) y A cidade dos Césares (1992). Igualmentente Alfredo Conde partía entonces de una posición privilegiada con Breixo (1981) y, sobre todo, Memoria de Noa (1982), con las que supo dar el salto definitivo hasta la también alegórica y celebrada Xa vai o griffón no vento (1984), desde cuya publicación se entregó a bizantinismos y devaneos que decepcionaron a sus lectores.

Pero aquellos años fueron ingratos para todo lo que no fuese novela, y de ello se resintieron otros autores igualmente destacables pero de obra genéricamente dispersa. Entre ellos está Úrsula Heinze, que alternó sus conquistas novelescas ( $O$ soño perdido de Elvira $M ., 1982$ ) con la literatura infantil, la crónica y la poesía, pero que recuperaba el pulso narrativo en 1993, con $\mathrm{Cul}$ pable de asasinato (Premio Blanco Amor). Paco Martín se condujo como un excelente creador en el terreno del fantástico: recordemos su memorable Das cousas de Ramón Lamote (1985), tal vez demasiado heterogéneo para la época; de hecho, habría que esperar hasta la siguiente década para recuperar al formidable narrador de Tres historias para ler á noite (1992).

También merece la pena referirse a un narrador tan constante como irregular que desde aquellos años se viene abriendo paso con muy diversas aportaciones. Se trata de Xosé Fernández Ferreiro, que si bien comienza ensayando una reivindicación de las producciones "de kiosco", pasará poco después a un tipo de narración más convencional. Así, desde el moderno western A morte de Frank González (1975) se acerca a la novela negra con Corrupción e morte de Brigitte Bardot (1981) y aun a la ciencia ficción con Reportaxe cósmico (1983), para buscar las aguas más remansadas que le llevan en 1991 a ganar el Xerais con Agosto do 36.

En cualquier caso, de entre aquella nutrida nómina que registraban los primeros años 80 , pocos escritores superarán el vacío de valores (literarios y sociales) que se produce en el período preautonómico. De hecho, la sensación de lo efímero gravita sobre la mayor parte de ellos, a pesar de sus razonablemente periódicas publicaciones, e incluso los que han logrado dejar constancia posterior de su nombre sólo lo han conseguido después de una ardua travesía del desierto: éste ha sido el caso de Xavier Alcalá y Alfredo 
Conde, más privilegiados que Úrsula Heinze y Paco Martín, por citar algunos nombres ${ }^{2}$.

\section{D) LLEGADA DE AUTORES PROCEDENTES DE OTROS REGISTROS LITERARIOS}

Pero la habilitación del hasta entonces casi inexistente panorama narrativo estable se habría de completar mediados los 80 con el desembarco de una nueva generación de nombres que tanto por edad como por formación se han desvinculado de la promoción del postfranquismo. Nos hallamos en los albores del desarrollo autonómico y el interés de la comunidad se centra más en la expresión heterogénea (se acaban de iniciar las emisiones de la televisión autonómica) que en la singularidad del canto subjetivista. Quizá se deba a ello la masiva entrada en la narración de autores dedicados hasta ese momento a la lírica: los nuevos - y menos nuevos- baluartes del lenguaje poético como Ramiro Fonte, Darío Xohán Cabana, Manuel Rivas y Manuel Forcadela (acompañados de los también poetas Ramón Caride Ogando, Xosé Miranda y Xosé Fernández Naval, entre otros) crean de forma súbita y espontánea el eje de una misma vocación novelística que se desarrolla desde dos polos bien diferenciados: el de la reflexión nacional, por un lado, y el de la literatura de género, por otro. En cuanto a los sucesos narrativos de este último cuarto de siglo nos detendremos más en el comentario del período moderno que se inicia hacia 1985 , y esto no por su inherente y especial incidencia artística -en cuyo caso será constatada-, sino a fin de detallar los cambios que se han ido produciendo en este terreno e informar sobre los hechos socialmente más celebrados.

Habrá pues que comenzar con Darío Xohán Cabana, representante fundacional de la primera alternativa señalada. En efecto, Cabana trabaja sobre los referentes mítico-líricos del imaginario nacional gallego, recreando en sus obras una fabulosa y caballeresca Edad Media; su universo ficcional rebosa reminiscencias artúricas, cunqueirianas y ferrinianas y en él es constante la revisión de la Historia (casi siempre asociada al frustrado rey García) desde una perspectiva ideológica restrictiva. Este enfoque, que continúa de algún modo los pasos iniciados unos años atrás por Víctor F. Freixanes $(O$ triángulo inscrito na circunferencia), y toma como punto de referencia la figura (ideológica y literaria) de Méndez Ferrín, fue bien acogido por los lectores desde su aparición, que podemos situar en 1989 con la muy satisfactoria Galván en Saor (Premio Xerais de ese año) y en lo sucesivo años siguientes con las monocordes (aunque popularizadas) Fortunato de Trasmundi (1990), Cándido Branco e o cabaleiro negro (1992) y Morte de rei (1997). A este ciclo hay que sumar el libro de relatos Vidas senlleiras (1992), que constituye un logra-

\footnotetext{
2 Prueba del auge de ese género ya de por sí fuerte es la "desaparición" de autores entregados a las estructuras cuentísticas, como Xosé Manuel Martínez Oca e Ignacio Taibo, a quienes se quiso imponer la trayectoria general que les debía llevar al buen camino de la "gran novela".
} 
do acercamiento a las posibilidades líricas del mundo comtemporáneo, pero también se resiente de esa onerosa épica con que se canta la moderna historia campesina.

En la misma línea se sitúan las últimas producciones de Manuel Rivas, particularmente En salvaxe compaña (1993), en cuyo universo ficcional se mezclan, por un lado, el torbellino de las pasiones humanas en el deteriorado mundo de los valores tradicionales del rural y, por otro, la sombra mítica del referente nacional por antonomasia: el rey García y su corte de almas en pena. En Rivas aparece como factor prioritario el tratamiento del moderno mundo rural en su difícil adaptación a los sistemas urbanos, y elabora con frecuencia situaciones humanas que muestran los sucesivos conflictos de tensión y asimilación entre ambos mundos. Un tratamiento menos global y teorizante, pero mucho más sugerente es el que consiguió imprimir en gran parte de los cuentos de ¿Que me queres, amor?, y de forma singular en la pieza A leiteira de Vermeer. De esta preocupación por los rasgos de la sociedad gallega había nacido, ya en 1989, Un millón de vacas, una colección de estampas y relatos de carácter fragmentario que fue acogida por el público (especialmente en la enseñanza) con un enstusiasmo inusitado, sobre todo si tenemos en cuenta que la fuerte apuesta por el rupturismo no se compensaba con el debilitado factor conceptual, que aún lo sería más en Os comedores de patacas (1991), fallido intento de novela pero con satisfactoria vida comercial.

En cuanto al resto de los poetas que indagan en las formas narrativas, una segunda vía se abre ante ellos. De hecho, como se adelantaba antes, todos se entregan de forma repentina a la exploración de los mecanismos "de género". Esta dinámica se inicia en 1989 con As regras do xogo (R. Fonte), Sangue sobre a neve (M. Forcadela) e $O$ crime da rúa da moeda vella ( $\mathrm{R}$. Raña). Curiosamente, todas estas aportaciones coinciden en torno al género negro, estrenado por Carlos Reigosa en 1984 con Crime en Compostela. Después de este camino (que desde ese momento y hasta hoy cobra un insólito auge en las letras gallegas) se van desarrollando de forma paulatina, y con un discreto éxito de recepción, otros como la ficción científica, la de terror y, en menor medida, la erótica.

En cualquier caso, conviene recordar cómo este acercamiento a la literatura popular es común a todos los procedentes del género poético, incluyendo entre ellos la fantasía futurista de Cabana en $O$ cervo na torre (1994) y la parcial recurrencia a la ficción delincuente de Rivas en $O$ s comedores de patacas. Del mismo modo, el también poeta Xosé Miranda ha combinado el tratamiento de referentes míticos (Historia dun paraugas azul, 1991) con la narración detectivesca (A tres bandas, 1995) y con la muy sólida creación del moderno fantástico gallego (con especial y magnífica presencia del terror) en $A$ biblioteca da iguana (1994), A neve e a cadeira (1994), Vestio (1995) y $O$ demo á orella (1997). En esta última línea no se podría dejar en el olvido la obra de Xesús Manuel Valcárcel, que desde 1985 (Soños nocturnos) emprende una turbulenta pero muchas veces brillante carrera narrativa en torno al fantástico de naturaleza siniestra, donde las fuerzas de lo irracional cobran una intensidad 
existencial y de particular significación social: Capitán lobo negro (1995) y Os ollos da sentinela (1997) así lo atestiguan.

De este modo, al filo de 1990 todas las generaciones formadas en el franquismo habían tomado las riendas en el terreno literario: los nacidos en la postguerra habían hecho posible la consolidación de la prosa y de la narración en un crítico momento de fuertes cambios sociales, dominando el espacio literario desde 1975 hasta inicios de los 80 . Las nuevas generaciones de la transición democrática también abandonaban hacia comienzos de esa década el individualismo de la poesía para centrarse en la mucho más comunitaria y compleja estructura novelesca, que desarrollan especialmente desde 1985. De toda esta organizada amalgama surge un espacio literario en lengua gallega donde el mito de la gran novela ya no es una procupación primordial, sino que ese lugar pasará ahora a ocuparlo la necesidad de articular un universo multiforme capaz de representar y de satisfacer a la variopinta comunidad que se está formando. Una vez creado el centro específico, se imponía dotarlo de los necesarios satélites.

\section{EXPANSIÓN Y PERIFERIAS}

Hemos aludido en varias ocasiones a la fecha de 1985 como el momento fronterizo a partir del cual se operan los cambios en la dinámica narrativa: es el punto cenital de la "Promoción de los premios" y también el de arribada de los poetas vertidos a la narración. Pero significa igualmente la señal de salida para una alternativa que en aquellos años pasará casi inadvertida, como muestra de la antojadiza actualidad, que, sin embargo, se fue imponiendo de allí en adelante. De hecho, es en esa fecha cuando asoman tres volúmenes que ahora merece la pena tener en cuenta: Historia do rock'n roll, de Antón Reixa, que, además de los criterios poéticos, supone la subversión del principio de género literario y aun musical.

\section{A) LA POPUlaRIZACIÓN DE LO RENOVADOR}

Todo ben, de Manuel Rivas, primera entrega de lo que, como ya se ha señalado, tomaría el camino de una muy moderna reflexión sobre la razón gallega. El tercer título, Caixón desastre, de Suso de Toro, se perfila entonces como diferente a la producción media y hoy, a pesar de su muy relativa trascendencia, sirve para comprender la trayectoria del autor.

En efecto, hacia 1985 nos hallamos a las puertas del verdadero cambio, anunciado por las tres calas a las que hemos hecho referencia, que evidencian 
la voluntad rupturista con que algunos autores asumen el acto literario; el hecho de que estos tres nombres sean desde ese momento aceptados por el gran público pone de manifiesto hasta qué punto sus producciones son representativas de un espíritu comunal. En cualquier caso, este momento supone la aceptación del rupturismo como moneda de uso común, aunque en estos autores funcione más como etiqueta definitoria de la voluntad que como una realización artística: a los ránkings de ventas, como a los militares, el valor se les supone. En cuanto a esto, un caso paradigmático es el de Suso de Toro.

Hacia el final de los 80 , De Toro ya había enunciado las dos sendas subversoras - y, quizá por ello, muy bien acogidas por el público - por las que se reconocerá su andadura narrativa, sobre todo, discursiva: la tendencia a la cotidianeidad (reducción de diversos conceptos a una medida coloquial) que se daba en los fragmentos de Polaroid - 1986- y la densidad de los submundos de Land Rover - 1988 - En los años siguientes el autor frecuenta diversas fórmulas "de consumo", desde la novela de la delincuencia Ambulancia (1990) hasta la narrativa juvenil al estilo ciencia-ficción. En 1997 el Blanco Amor de novela por Calzados Lola, una revisión de Ambulancia en la que destacan la agilidad discursiva y la disposición secuencial —eminentemente cinematográfica-.

Sin embargo, de cara a la narración literaria, debemos hacer un alto en 1993 con la aparición de Tic-Tac. De hecho, la publicación de este volumen convierte a su autor, desde los medios de comunicación y para una parte de la crítica, en un abanderado de la postmodernidad; de hecho, se cita el decidido fragmentarismo en las historias, en el discurso y aun en la configuración del pensamiento de alguno de sus personajes. Tic-Tac es una reflexión sobre el paso del tiempo, sobre el pasado y las emociones del ser. Con este título se puede decir que Suso de Toro adquirió el nombre definitivo dentro de las letras gallegas como portavoz de la estética postmoderna y, con ella, como sustentador del llamado "pensamiento débil". En efecto, De Toro ha aportado el valor de la exploración; ha intuido (más que materializado) la propuesta rupturista y ha sabido crear una imagen popular.

Vemos así como un modo de narración no convencional entra en nuestro panorama literario de un modo más teórico y voluntarioso que realmente logrado: recordemos que tanto Rivas como De Toro - y éste en mayor medidason los preferidos del público - sobre todo escolar-, mientras que luchan con la crítica para deshacerse del sambenito "de consumo".

\section{B) El CAMINO DEL RUPTURISMO}

En cualquier caso, un camino de nuevas formas se insinúa ante los lectores, y desde comienzos de los 90 está muy bien trazado por escritores que en el terreno de la popularidad ocupan una segunda fila, inmerecida en compara- 
ción con sus valores artísticos. Éste es el caso, entre los primeros en intentarlo, de Xelís de Toro, que hasta el momento sólo es autor de tres piezas bien distintas pero de cuyos magníficos resultados cabría esperar una continuidad. Además de relatos breves aparecidos en diferentes medios, Xelís de Toro saltó a la fama en 1989 - bajo el pseudónimo de Roque Morteiro-con la novela negra Seis cordas e un corazón, hábil y divertidísima fabulación de carácter absolutamente iconoclasta que situó a su autor en posición inmejorable respecto al público y la crítica. Non hai misericordia (1990) es un ingenioso crucigrama de historias urbanas que muestran la soledad de unos corazones sometidos a la violencia del medio y que mereció el Premio Cidade de Lugo. La última de sus producciones, en 1994, es Terminal, una colección de textos heterodoxos y fragmentarios que su autor combinó con performances escénicas; evidentemente, su carácter vanguardista no hizo de Terminal un éxito de ventas.

Otro ejemplo del cambio que se da en estos años se produce con la recuperación para la narrativa de Xosé Cid Cabido, un autor ya frecuente (pero desafortunado) en los 80. En su caso, la revelación se desarrolla de forma paulatina, aunque hay que partir de 1991, en que se publica la colección de cuentos Días contados; en este volumen Cid Cabido continúa explorando las situaciones de absurdo que habían caracterizado su prosa anterior, aunque se aprecia un cada vez mayor cuidado de las formas, en especial aquéllas en las que observa un sometimiento que casi diríamos matemático del canon estructural; esto se deja ver en la construcción de cuentos al estilo clásico. Pero su obra más lograda hasta el momento habrá de esperar hasta el Blanco Amor de 1994: Panificadora es una interesante parodia del relato policial y casi una parábola, que evidencia los conflictos sociales de nuestro mundo y, en concreto, de comunidades como la gallega, que el autor casi dibuja — con demasiados trazos de signo ideológico- en vías de extinción. Nace con esta pieza el evidencialismo, un concepto acuñado por Cid Cabido y que viene siendo una adaptación personal de lo que cualquier teórico encuadraría en la postmodernidad. Más recientemente (1997), la edición de los relatos Oralmente pola boca vuelve a mostrar al Cabido cuentista de sus mejores momentos (con el magistral cuento Patajorobi) junto a otro (tal vez demasiado "evidencialista") que apuesta por la provocación pero que no logra dotarla de un formato convincente.

Junto a estos nombres han aparecido a inicios de la década otros como Xurxo Borrazás, que desde un insospechado Cabeza de chorlito (1991) anunció la vía de una consciente des-realización. Y así fue como llegó en 1994 a la espléndida Criminal, con una trama que se origina en el más crudo rural, donde se desarrollan de forma trágica algunos mitos bíblicos (edénico, cainita...) y donde la multiplicidad toma forma de lenguaje, y que recibió con justicia el Premio de la Crítica. A esta novela ha seguido en 1997 Eu é, un alarde de creación deconstructiva realizada en un marco eminentemente temporal, en concreto a partir de la Revolución Francesa.

Trayectoria similar, aunque de escenarios distintos, es la que sigue Xavier Queipo, que en 1990 anuncia una elección innovadora dentro de la des-reali- 
zación con Ártico y más tarde con Diario dun nómada (1993). Los espacios de sus narraciones se sitúan con frecuencia en el terreno marítimo, en un universo de navegación que apunta al referente de Manuel Antonio, Konrad y aun Valéry. Hay, sin embargo, un enfoque menos endogámico en la colección de relatos Ringside (1994), que se mantiene en la estructura fragmentaria y en la estética ambigua. Finalmente, $O$ paso do noroeste (1997) ha supuesto la demostración del dominio narrativo con una novela que, además de las constantes aludidas, añade una visión globalizada sobre el tiempo de la Revolución - también- y hechos intemporales como el colonialismo y la crisis de los valores absolutos. En conjunto, y a pesar de las diferencias que los separan, toda esta promoción ha aportado a la literatura durante los primeros años de esta década la posibilidad de llevar a cabo una narrativa de actualidad y de calidad, en la que la técnica narrativa gana en innovación con las visiones parcializadas, en las que el minimalismo deja de ser la coartada de la medianía para ocupar un puesto funcional en la creación y en que la dispersión de los fragmentos sirve para un análisis totalizador de la evidente multiplicidad. Y todo ello con un afán renovador (de formas e ideas), cosmopolita y con los ojos puestos en un espacio abierto y múltiple, no necesariamente el marco referencial gallego.

\section{C) OTRAS PERIFERIAS}

Pero por si no resulta suficientemente reveladora la buena acogida que los lectores en general le dispensaron a las primeras renovaciones (por ser éstas más aparentes que otra cosa), y si no lo era también la popularidad de otros narradores-de-fragmentos (muchos de ellos, recordémoslo, ganadores de certámenes literarios), sí que va a ser altamente significativo el peso de auténticos demoledores de cánones que aparecen en escena a partir de 1995.

El primero en mostrar su peculiar concepción narrativa es Xavier Manteiga, que en 1995 se estrena con Morrer na herba, una obra en la que se apuntan los valores de la ya más consciente Sinfonía inacabada (1996). La formación audiovisual del autor salta a lo largo de estas páginas, en las que una trama de inaudita simpleza da lugar a un discurso enloquecido y errático, de ácido humorismo (no ajeno a la animación infantil y al cómic) y que avanza desbocado hacia un final amargo y absurdo. En cambio, imprime un certo giro su tercera entrega, Manancial (1997). Esta última, ganadora de un premio Xerais, se afirma sobre algunos aspectos de la narración convencional (de acusada huella faulkneriana), pero no renuncia a ese discurso de apresurada e irracional verborrea, al submundo de las conductas perturbadas, a los ambientes de densa tensión y a los conflictos que toman forma de barbarie. En definitiva, es una mirada cínica sobre el primitivismo de nuestro mundo lo que propone, esta vez con acierto, Manteiga. 
En la misma línea, aunque unos pasos por delante, se encuentran las aportaciones de Manuel Seixas, habitual del rock gallego y que se introdujo en el mundo editorial con Viñeron do espacio interior, una desconcertante exposición de seres atormentados que vacían su agobiante humanidad por medio de un discurso provocador, tanto en lo estético como en lo instrumental. En el mismo año, Seixas gana el Xerais de novela con $A$ velocidade do frío, en la que consigue reunir factores como la deshumanizada dureza del medio, la tortura de los personajes que en vano buscan un respiro, el uso epatante de la lengua más cotidiana y una necesidad de ruptura de los enlaces convencionales.

Resulta evidente, tras este breve repaso, que las soluciones de la actual narrativa gallega están buscando senderos de expresión alternativos, y para ello cuentan con el respaldo general de la comunidad, que no duda en canonizar cualquier vía de disensión si ésta sirve para recuperar espacios de expresividad, ámbitos recuperados de significación.

\section{D) OTROS FACTORES}

A esta somera descripción del estado de la narrativa actual hay que sumar algunos aspectos que, sin constituir un campo gravitatorio en sí, gozan de sintomática especificidad. Eso sucede, por ejemplo, con el mundo de la literatura femenina, exiguo pero bien representado. $Y$ en este punto hay que hacer una salvedad inicial, y es que la mayor parte de las escritoras gallegas simultanean sus producciones "generales" con las dedicadas al mundo infantil y juvenil, que en ocasiones sirve como laboratorio o como rampa de lanzamiento para la experimentación literaria. Para redondear la apreciación, cabe añadir que las aportaciones femeninas son principalmente de tesis: dominan tanto en la poesía como en buena parte de la teorización.

En cualquier caso, la ficción no viene de la concepción de un grupo autorial, sino de francotiradoras que luchan en terreno adverso. En estas dos décadas coexistieron los nombres más conocidos de Úrsula Heinze ( $O$ soño perdido de Elvira M., Culpable de asasinato) y María Xosé Queizán (Amantia, A semellanza) con otras realizaciones menos frecuentes, como las de Margarita Ledo (Mamá-Fe) y Marina Mayoral (Unha árbore, un adeus). Se trata en todos los casos de autoras con un bien marcado corpus literario a las que en los últimos años sa han ido sumando otros pocos nombres, entre los que destaca por mérito propio el de Marilar Aleixandre, autora hasta el momento de una interesante novela (Tránsito dos gramáticos, 1993) en la que se mezclan en buena conjunción de dosis la ficción futurista y la detectivesca, creando una compleja trama en la que el tratamiento del tiempo cobra un papel destacado. Su siguiente volumen, Lobos nas illas (1996), recoge una colección de relatos de corte diverso y a los que el enfoque femenino dota de un intenso interiorismo. 
Otro de los aspectos que llaman la atención en esta última parte de la década es el interés con que los autores en general han recuperado la fórmula del relato. Hay que tener nuevamente presente la importancia simbólica de la novela durante la época preautonómica y el afán con que fue creada (del que se deriva el riquísimo panorama actual). Y también conviene puntualizar que, a pesar de la adscripción cada vez mayor a la estética fragmentarista, las recientes y numerosas colecciones de relatos casi nunca vienen a coincidir con ese tipo de rupturismo, sino más bien con una visión reducida (parcializada) del universo ficcional. En este sentido, desde 1995 volvieron a ese género novelistas impenitentes como Alfredo Conde y Xosé Fernández Ferreiro ( $C o$ medo nas mans), desembarcaron en él autores itinerantes (es el caso genial de Gonzalo Navaza, que a sus juegos de palimpsestos ha sumado Erros e Tánatos, bien merecido crack de ventas), al tiempo que menudeaban las antologías sobre los temas más disímiles (cine, terror, policial, solidaridad, fantasía...).

\section{PANORAMA GLOBAL}

Para finalizar, si una sucinta pincelada pudiera abarcar, estratificada, la producción narrativa de este casi cuarto de siglo, podríamos trazarla así: dos nombres consagrados (Casares y Méndez Ferrín) sustentan de forma brillante y espaciada sendos lugares patriarcales a la cabeza de la república literaria. En orden al proceso de canonización (que suele coincidir con la cronología de los autores) les sigue una nutrida nómina de autores que han conseguido acreditar y aquilatar su calidad narrativa, sea a lo largo del tiempo, sea en la intertextualidad o sea en la promiscuidad de los géneros; son autores como Víctor F. Freixanes, Xavier Alcalá, Úrsula Heinze, Alfredo Conde, Paco Martín y un etcétera cuya omisión siempre es penosa (además de injusta). Una pléyade que antes fue poética reflexiona sobre la identidad (Darío Xohán Cabana, Manuel Rivas...) se abre en exploraciones por la literatura considerada popular, y a esos nombres ya conocidos (Ramiro Fonte, Xosé Miranda...) se unen otros de nuevo cuño (destacan las tres entregas "negras" de Aníbal Malvar).

Coexisten las creaciones de discretos y dignísimos narradores (Xosé Ramón Pena, Marilar Aleixandre, Xesús Rábade Paredes...) con las atrevidas propuestas de los más jóvenes o, simplemente, los más atrevidos, que han hallado un lugar (privilegiado) bajo el sol siempre cambiante del cielo de Galicia. 